\title{
Elites estatais e industrialização: ensaio de comparação entre Brasil, Argentina e México (1920-1970)
}

\author{
RENATO PERISSINOTTO \\ PAULO ROBERTO NEVES COSTA \\ WELLINGTON NUNES \\ ANGELA ILHA*
}

States elites and industrialiozation.

The purpose of this article is to stress on the importance of the sociology of state elites to fully understand developmental processes. With that purpose in mind, we comparatively analyze the industrialization process in Argentina, Brazil and Mexico from 1920 to 1970 . Our analysis shows that although Argentina was in a much better condition to initiate its industrialization process in the early thirties, it was overtaken by Brazil and Mexico already in the late fifties. The article suggests that this took place because Brazil and Mexico, among other things, had a state elite willing to take development seriously, whereas Argentina lacked it.

Keywords: Brazil; Argentina; Mexico; industrialization; state elites.

JEL Classification: Z13.

No seu ensaio sobre a psicologia social das religiões mundiais, Max Weber afirma que o conteúdo assumido pela ética econômica das religiões depende não apenas das fontes propriamente religiosas (ainda que dependa principalmente delas), mas também dos atributos das camadas socialmente disponíveis para assumirem a tarefa de elaborar a teoria dessas crenças e conduzir a sua aplicação prática. As especificidades desses grupos, diz Weber, são sociologicamente significativas na

\footnotetext{
* Renato Perissinotto é professor do Programa de Pós-Graduação em Ciência Política (PPGCP) da UFPR e pesquisador do CNPq. E-mail: monseff@gmail.com; Paulo Roberto Neves Costa é professor do PPGCP da UFPR e pesquisador do CNPq. E-mail: paulocostaufpr@gmail.com; Welington Nunes é mestrando do PPGCP da UFPR e bolsista Capes. E-mail: gton_nunes@yahoo.com.br ; Angela Ilha é graduanda em Ciências Sociais na UFPR. E-mail: ilha.angela@gmail.com. Submetido: 6/maio/2013; Aprovado: 25/novembro/2013.
} 
medida em que suas características afetam o desenvolvimento futuro dessas religiões. Nesse sentido, perguntar-se "quais grupos" estão disponíveis num dado contexto para se transformarem em "portadores sociais" (träger) da nova crença é fundamental do ponto de vista da Sociologia ${ }^{1}$.

Pensamos que o problema da industrialização em países de economia primário-exportadora pode ser colocado nos mesmos termos. Quando esses países se defrontam com a conjuntura crítica ${ }^{2}$ de 1929 e a possibilidade de trilhar o caminho da industrialização se apresenta é pertinente perguntar quais deles contam com grupos sociais dispostos a se tornarem os portadores políticos dessa tarefa e como seus atributos afetam a natureza do desenvolvimento econômico posterior.

Essa questão, aliás, tem forte tradição entre alguns economistas que insistem na importância de fatores "volitivos" para se entender o processo de transição de sociedades agrárias para sociedades industriais. Nessa perspectiva, para que as condições estruturais determinadas pelos choques externos se traduzam efetivamente em industrialização é preciso contar com a presença de agentes estatais portadores de uma ideologia industrializante e dispostos a criar condições político-institucionais para o seu avanço. Por essa razão, "uma abordagem principalmente política da história industrial" nesses casos seria inevitável (Gerschenkron, 1976, p. 52). Hirschmann defende posição similar ao enfatizar a importância da presença de agentes estatais dispostos a tomarem "decisões desenvolvimentistas" e a promoverem as reformas institucionais necessárias para a industrialização (1964, pp. 5, 11, 26, nota 33).

Este ensaio pretende sugerir uma interpretação acerca das diferenças de desempenho nos processos de industrialização de Brasil, Argentina e México a partir dessa perspectiva analítica. Não se trata de um texto histórico ou monográfico com pretensões de apresentar ao leitor dados originais. A nossa intenção é, fazendo uso de um desenho de pesquisa comparativo, sustentar a hipótese de que a presença no Brasil e no México de um grupo social disposto a "tomar decisões desenvolvimentistas" (Hirschmann, 1964) ajuda a entender por que esses dois países, apesar de situarem-se num ponto de partida muito inferior, foram capazes de promover com mais intensidade do que a Argentina a industrialização ao longo do período aqui analisado. A comparação, portanto, sugere que a presença de uma elite estatal subjetivamente orientada para a industrialização e dedicada à construção de um aparato estatal e de uma burocracia econômica estável capaz de conduzi-la é condição essencial (mas não suficiente) para entender essa diferença.

$\mathrm{O}$ texto se divide em três partes. Na primeira, apresentamos uma rápida justificativa sobre a pertinência da comparação entre esses três países; na segunda parte, apresentamos dados que ilustram a diferença de ritmo, intensidade e qualidade entre os seus processos de industrialização; na terceira parte apresentamos, de forma

\footnotetext{
${ }^{1}$ Ver Weber, 1979, pp. 310-312, 322-323 e, especialmente, pp. 326-330, e Kalberg, 1994, pp. 58-62.

${ }^{2}$ Uma conjuntura crítica caracteriza-se, primeiro, pela possibilidade de mudanças estruturais em uma da sociedade; em segundo lugar, pelo tipo de reação a essa possibilidade de mudança, e, por fim, pela produção de legados que alteram a ordem social previamente existente. Cf. Collier e Collier, 1999, p. 30.
} 
necessariamente panorâmica, argumentos plausíveis que permitem vincular tais variações no processo de industrialização às variações na natureza das elites estatais e nos contextos institucionais e ideológicos que caracterizavam esses países ${ }^{3}$.

\section{POR QUE COMPARAR BRASIL, ARGENTINA E MÉXICO?}

Brasil, Argentina e México são países comparáveis? Acreditamos que a resposta é afirmativa no que diz respeito ao delimitado problema da industrialização ${ }^{4}$. Os três países nascem economicamente como países exportadores de bens primários para o mercado internacional, ocupando, portanto, a mesma posição na divisão internacional do trabalho. São países cuja dinâmica econômica é, inicialmente, determinada fundamentalmente pelos humores do mercado externo e pela capacidade de suas respectivas economias exportadoras responderem às variações da economia mundial capitalista.

Como resultado desse predomínio estrutural do setor exportador nos três países, alguns outros setores da economia tendem a ter a sua dinâmica definida pela dinâmica das exportações. Este é o caso do setor agrário cuja produção é destinada ao mercado interno e, em particular, da própria atividade industrial. Estudiosos dos três países aqui analisados revelam que suas economias foram suficientemente dinâmicas e vigorosas para gerarem um setor industrial que encontrou nela mercado para os seus produtos e fonte de divisas externas com as quais comprar bens de capital no exterior. Consequentemente, mesmo antes de entrarem definitivamente na rota da industrialização, já possuíam parques industriais relativamente amplos e diversificados e que serviriam de plataforma inicial para o processo de substituição de importações que iria vigorar depois de 1930 em todos eles 5 .

\section{INDUSTRIALIZAÇÃO NO BRASIL, NA ARGENTINA E NO MÉXICO}

No entanto, apesar da presença significativa da indústria já no final da década de 1930 nos três países, a Argentina é, nesse momento, o país com o mais robusto

\footnotetext{
${ }^{3}$ Por "elites estatais" entendemos os indivíduos que detêm o controle das principais instituições do aparelho estatal, no nosso caso, principalmente, aqueles que controlam o poder executivo e as agências econômicas do Estado. Por "contexto institucional" entendemos o conjunto de agências econômicas do Estado criadas ao longo do período e as formas institucionais que definem o modo dessas agências se relacionarem com os setores econômicos estratégicos, notadamente os empresários. Por "contexto ideológico" entendemos o conjunto de "esquemas mentais" a partir dos quais o problema do desenvolvimento econômico era apreendido e que serviam como guias práticos para a ação.

${ }^{4}$ Skocpol e Somers (1997, p. 90) e Collier e Collier (1991, p. 14, nota 15) observam que a aplicabilidade da análise histórica comparativa só é viável se o problema a ser pesquisado for muito bem delimitado. Ninguém, de fato, compara "países" ou "sociedades" inteiros.

${ }^{5}$ Para uma breve descrição sobre as economias brasileira, argentina e mexicana antes da crise dos anos 1930, ver, respectivamente, Fausto, 1996; Romero, 2006, e Garrido, 2002. Para o crescimento da indústria já na década de 1930, ver Bulmer-Thomas, 1998, p. 104.
} 
parque industrial, seguida pelo México e pelo Brasil. A diferença se mostra em termos de produção per capita, mesmo quando levamos em conta as diferenças no tamanho da população. Em 1930, a população brasileira era três vezes maior que a argentina (33 milhões contra 11 milhões de habitantes) e próximo dessa proporção por volta de 1939 (Merrick, 1998, p. 7). Porém, a produção industrial per capita na Argentina, em 1939, representava cinco vezes mais que a produção per capita brasileira. O México, com uma população de 16,5 milhões, em 1930, também fica muito abaixo nesse quesito (Bulmer-Thomas, 1998, p. 104). No que se refere ao peso da produção industrial em relação ao PIB, a situação permaneceu basicamente a mesma durante a década de 1940. No que diz respeito a Brasil e Argentina, segundo Rosemary Thorp (1998, p. 125), em 1940, a indústria representava $23 \%$ do PIB argentino e $15 \%$ do PIB brasileiro. Em 1945, os percentuais eram $25 \%$ e $17 \%$, respectivamente.

Porém, à medida que dados mais recentes são apresentados a superioridade argentina se desvanece pouco a pouco. Com relação ao aumento da produção industrial em relação ao PIB, por exemplo, Ffrench-Davis et al (1998, pp. 186-187) revelam que em 1950 a participação do setor manufatureiro no PIB aumenta sistematicamente no Brasil e no México num ritmo mais intenso do que na Argentina e os PIBs brasileiro e mexicano crescem quase três vezes mais que o argentino. Segundo Dorfman, se tomarmos os anos de 1960-62 e 1979-81, a participação da Argentina no produto industrial continental passa de $18,5 \%$ para $10 \%$, enquanto o Brasil sobe de 33\% para 40,5\% (1983, pp. 570-576).

As disparidades, porém, vão além de diferenças quantitativas na produção industrial e na sua participação no PIB. Brasil e México se saíram melhor que a Argentina também no que diz respeito à estrutura industrial e à produtividade. Segundo Dorfman, a leitura dos dados referentes à estrutura industrial revela, sem sombra de dúvidas, que a Argentina foi perdendo posições em praticamente todos os componentes econômicos e industriais, tendo sido, ao longo do período aqui analisado, claramente ultrapassada por Brasil e México também nessa dimensão do processo de industrialização ${ }^{6}$. Dorfman avalia que o tamanho da defasagem vivenciada pela Argentina no setor de bens de capital deveu-se à falta, neste país, de incentivos coerentes e contínuos para esse ramo da indústria, faltando-lhe mercados e inviabilizando as ampliações (1983, p. 221).

\section{FATORES POLÍTICOS DO DESENVOLVIMENTO ECONÔMICO: INSTITUI- ÇÕES, IDEOLOGIA ECONÔMICA E ELITE ESTATAL}

Segundo Sikkink (1991), o melhor desempenho da industrialização brasileira está intimamente vinculado a fatores institucionais e ideológicos. Esses dois primeiros fatores, porém, dependem intimamente de um terceiro, a saber, a presença de uma elite estatal disposta a tomar medidas desenvolvimentistas, entre elas a cons-

${ }^{6}$ Ver também Cortés Conde (2009, pp. 6-8). 
trução de instituições para implementá-las. Acreditamos que esta variável se encontrava presente no Brasil e no México e ausente na Argentina.

Do ponto de vista institucional, uma diferença marcante entre os três países é a presença de um processo contínuo de construção de agências estatais voltadas para a assessoria técnica e a formulação de políticas econômicas desenvolvimentistas. Nesse aspecto, o Brasil se destaca, seguido por México e Argentina.

No Brasil, foram muitas as instituições importantes quanto a esse aspecto, nem todas elas diretamente voltadas para a formulação de políticas econômicas. Uma rápida leitura da ampla literatura sobre o tema revela ao leitor um alto número de instituições duradouras, institucionalizadas e dotadas de capacidade técnica e política para assessorar, formular e implementar políticas econômicas desenvolvimentistas. O Conselho Federal de Comércio Externo, o Departamento Administrativo do Serviço Público, o Itamaraty, o Banco do Brasil e suas carteiras (Cexim e Cacex), o Banco Nacional de Desenvolvimento Econômico, a Fundação Getulio Vargas, a Superintendência da Moeda e do Crédito, a Assessoria Econômica da Presidência da República e os inúmeros conselhos estatais criados ao longo do período são de fundamental importância não apenas do ponto de vista da formulação de políticas econômicas, mas também no que diz respeito à formação de técnicos e servidores que viriam a constituir a burocracia econômica estável a que nos referimos acima. Muitas dessas instituições funcionaram como equivalentes funcionais dos cursos de economia, que apareceram apenas no final da década de 1930 e demoraram muito para se consolidar (Martins, 1975; Leopoldi, 1992, 2000; Bielschovsky, 2000; Draibe, 1985; Gouvêa, 1994; Loureiro, 1997; Santos, 2006) ${ }^{7}$.

No México, papel semelhante foi exercido pela NAFINSA (Nacional Financeira, S.A.). Para Luna (2009), o Estado mexicano, no período pós-revolucionário (1920-1950), interferiu ativamente na economia e outorgou créditos às atividades produtivas com o objetivo de reativar o crescimento e o nível de emprego. Neste contexto, modificou-se a forma de enfrentar os problemas econômicos e sociais e desencadeou-se uma estratégia de fomento industrial e geração de emprego. Com esta finalidade, foi criada a NAFINSA em 1934 (p. 80). Já para Arès (2007), um dos fatores que possibilitou a ascensão da agência de um papel secundário nos primeiros anos de sua criação à condição de ator político indiscutível foi o profissionalismo e a habilidade política de sua direção (p. 210). Essa tese é corroborada por Maxfield (1993, p. 242), que sustenta que a criação de uma divisão de pesquisa industrial pela NAFINSA em 1941, a partir da qual passou a planejar suas intervenções, fez com que a agência afirmasse sua competência exclusiva na esfera econômica, sobrepujando, inclusive, o Banco do México.

A Argentina teve um começo auspicioso quanto a este ponto já na primeira

\footnotetext{
${ }^{7}$ Não são, portanto, apenas as instituições militares e a Cepal que fornecem treinamento para os burocratas do Estado brasileiro nesse período, como afirma Schneider (1991, pp. 221-222 e 228). Com relação a esse ponto ver Galvêas, 1990, p. 8 e Gouvêa, 1994, cap. I. Ver também Santos, 2006, cap. I, que revela como a Assessoria Econômica da Presidência, criada durante o segundo governo Vargas, foi composta fundamentalmente por técnicos oriundos do setor público.
} 
metade dos anos 1930, quando Raúl Prebisch não só reuniu em torno de si competente equipe econômica, mas também construiu o Banco Central Argentino em 1935, instituição que adquiriu fama internacional. O Banco Central, no entanto, nunca foi uma instituição de orientação desenvolvimentista e com a chegada de Perón ao poder foi ostensivamente submetido às injunções da política imediata ${ }^{8}$. Quanto a esse ponto, aliás, vale observar que a criatividade institucional de Perón foi sempre muito limitada. Segundo vários autores, todo o aparato institucional econômico do peronismo foi herdado do período anterior, à exceção do Instituto Argentino para la Promoción del Intercambio (IAPI), agência voltada para o controle do mercado externo e de cambiais. Em 1955, com a derrocada de Perón, o IAPI foi fechado (Morales, 1990, p. 46; Sidicaro, 2002, p. 55; Sábato, 1988, p. 172). Somente com Frondizi houve algum ensaio de invenção institucional (com a criação do Conselho Nacional de Desenvolvimento) e, pouco antes, com Aramburu, por meio da criação do Instituto Nacional de Tecnologia Agrária (1956) e do Instituto Nacional de Tecnologia Industrial (1957).

Parece haver acordo na literatura que foi no primeiro período de Perón (19461955) que o Estado argentino mais se expandiu. Nesses anos, as agências econômicas estavam frequentemente sob influência direta do Presidente e a maioria dos seus membros era indicada por razões exclusivamente políticas. Nesse sentido, é interessante observar que muitas das instituições criadas por Vargas sobreviveram ao seu criador e foram largamente utilizadas pelos seus sucessores para promover seus planos de desenvolvimento, como é o caso do papel central do BNDE para a implementação do Plano de Metas de JK, enquanto na Argentina as poucas instituições criadas por Perón despareceram após a sua queda?

\footnotetext{
${ }^{8}$ Prebisch observava: "Vargas supo formar cuadros, dio estructura moderna al Estado brasileño. Vea a Perón: dispersó con un gesto un equipo que me costó diez años formar. Decir eso debía dolerle. El equipo al que se refería había dado a la Argentina un avance quilométrico en la investigación económica en América Latina, y había hecho del Banco Central una institución admirada internacionalmente" (Celso Furtado, apud Donghi, 2004, p. 141, nota 5). Quanto ao desejo de modernização institucional de Prebisch e suas críticas a Perón, ver também Dosman, 2011, pp. 64, 74, 78, 242-43, 347. Sobre as frequentes mudanças nas nomeações de Perón para as agências econômicas, ver Gambini, 2007, vol. I, capítulos 1 e 4, e vol. II, capítulos 3 e 4. Quanto à preferência de Vargas por técnicos, ver Santos, 2006, p. 9.

${ }^{9}$ Ver, por exemplo, Benevides, 1979; Martins, 1976, p. 420; Draibe, 1985; Fonseca, 1987; Geddes, 1990; Sikkink, 1991, pp. 174-175; Willis, 1995. Devemos evitar, porém, qualquer perspectiva enviesada quando analisamos a história administrativa brasileira nesse período. Como Graham (1968) e Schneider (1991) revelam, muitas das reformas avançadas nesse período ficaram aquém do seu objetivo final, que era implementar um Estado burocrático pleno no Brasil. Quanto à mistura de "gramáticas políticas" dentro do Estado brasileiro, ver Edson Nunes, 1997. Sobre a capacidade de algumas agências estatais para formar uma burocracia econômica estável, ver Gouvêa, 1994, cap. I. Quanto à presença/ausência de uma burocracia econômica, ver Wirth, 1970, pp. 4-5; Daland, 1967, p. 92; Fonseca, 1987, p. 367; Bielschovsky, 2000; Martins, 1976, pp. 141 e 417; Leff, 1968, pp. 98-99 e 152 para o caso brasileiro; ver Mallon e Sourrouille, 1975, p. 9; Romero, 2006, pp. 100-01; Albertini e Castiglioni, 1985; Rouquié, 1971 para o caso argentino; ver Sikkink, 1991, pp. 169, 180-181, Fausto e Devoto, 2004, para uma abordagem comparativa.
} 
Os Estados brasileiro e mexicano foram mais eficientes também em se aproximar daquilo que Peter Evans (1995) chamou de "autonomia inserida". No caso do Brasil, todos os presidentes brasileiros deram continuidade ao "modo varguista" de lidar com os interesses empresariais, isto é, abrir as agências estatais às associações de classe e assim estabelecer um diálogo permanente com os mais importantes setores da economia. Essa organização corporativista do Estado foi importante fonte de estabilidade para o processo de formulação de políticas econômicas com forte orientação industrializante (Leopoldi, 1992, 2000; Diniz, 1978; Boschi 1979; Costa, 1991; Gomes, 1979; Schneider, 2004; Jauregui, 2004).

No México, a consolidação do sistema bancário mexicano nos anos 1930 constitui uma das melhores ilustrações da colaboração Estado-setor privado no país (Arès, 2007, p. 207; Hamilton, 1982, p. 80). Ortega (2012, p. 189) observa que, à medida que expandiam sua participação financeira no desenvolvimento industrial, durante as décadas de 1940 e 1950, os bancos de desenvolvimento incrementavam sua participação política. Isso possibilitou o surgimento dos grupos empresariais organizados politicamente (CANACINTRA, CONCANACO, CONCAMIN) e com íntima relação com a NAFINSA.

Ao contrário, o Estado argentino é caracterizado no período em questão por falta de autonomia inserida, mesmo sob Perón. Ali, a falta de qualquer mecanismo de representação societal representava um importante limite do processo decisório (Jauregui, 2000, 2004; Mallon \$ Sourrouille, 1975, p.p 3 e 154; Wynia, 1978, p. 15 e 54-79). Segundo Brenann, "Perón, diferentemente de Vargas, nunca foi bem-sucedido em estabelecer uma relação cooperativa proveitosa com os grandes empresários argentinos, a despeito de algumas tentativas nesse sentido" (1997, p. 129, nota 83). Segundo Jauregui (2004, pp. 64 e 65), somente após o peronismo é que se alterou a forma de articulação do governo com os empresários, mas sem implicar uma participação contundente dos mesmos na política econômica, a despeito do seu interesse em adotar formas de representação semelhantes àquelas do Brasil.

Essa infraestrutura institucional (ou a falta dela, no caso argentino) não é, contudo, uma resposta natural à crise de 1929, como nos querem fazer crer alguns economistas. Ela era, no caso brasileiro, o resultado de uma orientação ideológica baseada em esquemas mentais profundamente enraizados. Sikkink (1991), por exemplo, revelou a presença de uma atmosfera ideológica muito mais favorável ao desenvolvimentismo no Brasil do que na Argentina, tanto dentro como fora do aparelho estatal. Segundo ela, as clivagens ideológicas no Brasil e na Argentina eram bastante diferentes.

No Brasil, o campo ideológico quanto aos modos de pensar a economia estava claramente dividido entre apenas duas forças. De um lado, o liberalismo econômico tinha sido hegemônico desde o Império e atingiu o seu zênite durante a Primeira República. No entanto, mesmo durante este último período seria difícil qualificar como liberal a política econômica cafeeira conhecida como "valorização" (Topik, 1988; Perissinotto, 1994). Além disso, é importante notar a existência de um pensamento "desenvolvimentista" embrionário entre os militares e, o que é de 
enorme importância, no interior da elite política positivista do Rio Grande do Sul (Fonseca, 2011).

Depois de 1930, porém, os desenvolvimentistas iriam dominar claramente (ainda que não tranquilamente) a cena. Segundo Bielschowsky (2000, pp. 11-14 e 78129), os desenvolvimentistas negavam o mercado como locus mais eficiente para a alocação de recursos econômicos, defendiam a industrialização, o protecionismo, o planejamento e a intervenção do Estado como maneiras de promover a industrialização pesada e a autonomia nacional. Eles viram na Cepal uma fonte de inspiração e sistematização teórica, mas, como mostra amplamente Fonseca $(1987,2011)$, seus principais traços ideológicos eram partilhados por um importante setor da elite política brasileira muito antes do surgimento daquela agência. Ainda que o campo desenvolvimentista estivesse dividido entre uma ala nacionalista e um grupo muito mais tolerante quanto à presença do capital estrangeiro, ambos estavam juntos sempre que fosse necessário defender a ideia de planejamento e intervenção estatal contra os ataques liberais (Bielschovsky, 2000; Martins, 1976, p. 140).

No Brasil, o desenvolvimentismo tinha forte apelo também entre empresários (Sikkink, 1991; Fonseca, 1987; Bielschovsky, 2000; Leopoldi, 2000; Leff, 1968; Diniz, 1978). Já nos anos 1920 alguns empresários de São Paulo estavam em contato com ideias econômicas favoráveis à industrialização, como as do economista romeno Manoielescu, publicadas no seu livro Théorie du protectionnisme, cuja tradução para o português em 1931 foi patrocinada pelo Centro das Indústrias (Love, 1988, p. 24). Robert Simonsen, famoso empresário favorável à industrialização, não defendia apenas a implementação de tarifas alfandegárias, mas também mudanças estruturais na economia brasileira.

No caso do México, também parecia haver uma polarização clara no campo ideológico, com predominância, no pós-1930, daquilo que se pode chamar de um nacionalismo desenvolvimentista. Para Mathieu Arès, a criação dos bancos de desenvolvimento, particularmente da NAFINSA, ocorre no período de transição entre o modelo econômico liberal, que vigorou durante o período conhecido como Maximato (1924-1934), e o modelo de um Estado interventor funcionando como motor da industrialização nacional que se instalaria, definitivamente, a partir de 1940 (Arès, 2007, p. 207). Segovia (1968, pp. 355-356) sustenta que, sob o Cardenismo (1934-1940), o nacionalismo mexicano (sobretudo, o econômico) chegou ao seu auge e que a conjuntura internacional da Segunda Guerra produziu uma mudança "revolucionária": à luta de classes, reconhecidamente um dos fundamentos da vida no país, sucedeu a "unidade nacional” (1968, pp. 355-356).

Solís (1969), por sua vez, argumenta que, a partir de 1940, todos os presidentes mexicanos passaram a compartilhar determinadas características e metas como desenvolvimento econômico, tais como a preocupação com grupos sociais de baixa renda, a independência em relação aos investimentos estrangeiros, o respeito pelo sistema em vigor, entre outros. Dessa forma, o nacionalismo mexicano, ainda segundo o autor, influenciou na tomada de decisões econômicas e ajudou a manter a luta política fora do processo econômico (pp. 240-241). Assim, quando o desenvolvimento industrial passa a ser o "eixo central" da política econômica, após o 
amplo processo de distribuição de terras do governo Cárdenas (Ortiz, 1969, p. 503), pode se dizer que o processo de industrialização mexicano veio a se constituir em meta nacional (Santín, 2001; Ortega, 2012; Ortiz Mena, 2000).

A cena ideológica argentina é mais complicada. De acordo com Sikkink (1991), o campo pró-industrialista não estava unificado contra os liberais. O nacionalismo peronista era extremamente desconfiado dos desenvolvimentistas, que eram politicamente conduzidos por Arturo Frondizi e teoricamente organizados por Prebisch e pela Cepal. Essa desconfiança tinha profundas raízes em fatos políticos pretéritos, já que Frondizi e a UCR fizeram forte oposição a Perón e Prebisch foi conselheiro do Ministro da Economia de Aramburu em 1955. Ademais, Perón nunca foi de fato um defensor militante da industrialização pesada. De acordo com vários autores, sua política protecionista era muito mais destinada a fortalecer o mercado interno baseado em pequenas e médias empresas e garantir bens de consumo baratos para a classe trabalhadora do que expandir a industrialização pesada. Perón era um "mercado internista", não um desenvolvimentista (Albertini \& Castiglioni, 1985). Essa opção econômica não era, frise-se, o resultado de um cálculo político oportunista, mas já estava presente entre as principais preocupações do G.O.U., Grupo de Oficiales Unidos, grupo coordenado por Perón e que deu apoio político ao golpe de Estado de 1943 (Potasch, 1984, pp. 187-162; Gambini, 2007a, pp. 19-20).

Entre os empresários, havia muitos defensores de uma política econômica protecionista na Argentina. Com relação a esse ponto, Alejandro Bunge jogou papel similar ao de Roberto Simonsen no Brasil (Caravaca \& Plotkin, 2007). No entanto, para os discípulos de Bunge, que eram muito influentes até o final dos anos 1940, o processo de industrialização deveria ser orientado principalmente para o atendimento das necessidades básicas da população argentina e as indústrias pesadas não eram algo importante no seu pensamento econômico (Belini, 2006).

Portanto, como se vê, vários autores estão certos em enfatizar a importância das vantagens institucionais e ideológicas do desenvolvimentismo brasileiro e mexicano como uma base fundamental para entender o seu melhor desempenho industrial. No entanto, pensamos que o entendimento do surgimento desses fatores institucionais e ideológicos deve subordinar-se ao estudo da natureza da elite que assumiu o controle do poder estatal em momentos de inflexão da história política desses países. No que diz respeito ao Brasil e à Argentina, um bom ponto de partida é comparar os movimentos políticos ocorridos em 1930 em ambos os países.

De acordo com vários autores, o golpe de Estado que derrubou Hipólito Yrigoyen em 6 de setembro de 1930 foi uma reação conservadora dos setores pecuaristas dos pampas e dos liberais contra as ameaças à sua hegemonia política e econômica. Nesse sentido, o golpe de 1930 na Argentina não representou uma ruptura, mas a continuação da velha ordem (Waisman, 1987, pp. 130-31; Wynia, 1978, pp. 23-36; Albertini \& Castiglioni, 1985, pp. 3-4; Jauregui, 2000, pp. 70-73; Romero, 2005; Sidicaro, 2002, p.p 28-29). Como dito por Donghi (2004, p. 145), apesar de algumas tentativas de inovar no campo da política econômica, especialmente por Pinedo e Prebisch, as decisões tomadas nessa área dificilmente poderiam ser vistas como ino- 
vadoras. O liberalismo econômico permanecerá hegemônico depois de 1930 até 1943, quando os membros do G.O.U. e, alguns anos depois, Perón ascendem ao poder. Contudo, como dito anteriormente, esse deslocamento ideológico, ainda que de enorme importância em vários aspectos, não inaugurou um movimento em direção à industrialização pesada.

O golpe de Estado de 3 de outubro de 1930 no Brasil foi também um movimento conservador, mas de outra natureza (Martins, 1976, pp. 96-120). A elite política que assumiu o poder depois da queda da Primeira República tem sido qualificada de "fascista", "corporativista", "conservadora-modernizadora”, "populista”, "pragmática" ou "nacionalista". Ainda que todos esses rótulos tenham sua parcela de verdade, o mais importante traço ideológico de Vargas e sua entourage era sua forte orientação positivista ${ }^{10}$. Se as ideias de Augusto Comte não se constituíam no "fundamento teórico do desenvolvimento industrial”, como observado por Joseph Love $(1988$, p. 25), elas certamente operavam como um guia prático para ações políticas e administrativas. Enquanto tal, o "positivismo político" desse grupo tinha dois pilares: intervenção estatal e industrialização. Seu principal objetivo, no nível administrativo, era a construção de um corpo científico e profissional de servidores públicos; no nível econômico, o intervencionismo estatal deveria ser usado para promover a industrialização. É muito importante observar, porém, que esse traço ideológico não era um atributo pessoal de Vargas, mas uma ideologia amplamente hegemônica dentro do Partido Republicano Riograndense, partilhada pela famosa geração de 1907, que o acompanhou ao poder depois de 1930 e que incluía nomes como João Neves da Fontoura, Flores da Cunha, Lindolfo Collor e Osvaldo Aranha (Love, 1975; Bosi, 1992) $)^{11}$.

Essa orientação positivista estava presente também entre os militares, o que possibilitou, segundo Martins (1976, pp. 83 e 110), uma aliança civil-militar após a Revolução de 1930 que seria o sustentáculo dessa orientação desenvolvimentista imposta já no início dos anos 1930. A partir desse momento, uma elite política civil e militar, ideologicamente comprometida com os ideais desenvolvimentistas, encontrou um lugar seguro no interior do aparelho estatal ${ }^{12}$. Por isso, a partir desse mo-

\footnotetext{
${ }^{10}$ As observações a seguir são amplamente baseadas em Fonseca, 1987, pp. 43-143. Sobre o positivismo no Rio Grande do Sul ver, por exemplo, Love, 1975; Bosi, 1992; Hentschke, 2004; Noll, 2007; Alonso, 2007; Heinz, 2009; Fonseca, 2011.

${ }^{11}$ Como bem mostra Bresser-Pereira, esse período da história brasileira conjuga possibilidades estruturais com a presença de um grupo político capaz de, por meio de sua ação política, levar tais possibilidades a termo. Getulio Vargas concentrava em si, além dos atributos sociais, políticos e ideológicos de sua geração, a capacidade individual que fez dele o líder político inconteste desse período. Ver Bresser-Pereira, 2009. Sobre a "consciência industrializante" dos revolucionários de 1930 e como ela se materializa em instituições voltadas para a industrialização já nos primeiros anos posteriores à revolução, ver Fonseca, 2003. Desse mesmo autor, ver também Fonseca, 2012. Sobre esse mesmo ponto, ver Santos, 2006.

${ }^{12}$ Com relação a esse assunto, é importante insistir no papel central dos "tenentes", os rebeldes dos estratos mais baixos do Exército brasileiro, na eclosão da Revolução de 1930. O papel dos "tenentes” na modernização da sociedade brasileira é análogo ao papel dos baixos oficiais nas "revoluções a partir de cima" analisadas por Trimberger (1978). Sobre os “tenentes”, ver Conniff, 1978; Fausto, 1997, 1990;
} 
mento, o aparato estatal brasileiro materializa crescentemente nas suas agências econômicas uma mentalidade desenvolvimentista previamente existente capaz de estabelecer os parâmetros que definiriam a política econômica. Ao contrário, a ideologia desenvolvimentista na Argentina nunca se materializou em agências do Estado. Ela não era fraca apenas em termos políticos, se comparada com o liberalismo, mas também extremamente dependente do desempenho personalista de nomes como Frondizi e Frigerio. Quando JK, expoente do desenvolvimentismo brasileiro, foi eleito em 1956, o Brasil já tinha algo próximo de um Estado desenvolvimentista (Leftwich, 2000), enquanto, em 1958, o ano da eleição de Frondizi, expoente do desenvolvimentismo argentino, a Argentina estava muito longe disso.

O resultado dessa diferença foi que no Brasil se produziu uma burocracia econômica tecnicamente competente e estável. Como mostra a literatura sobre esse período (ver Leopoldi, 1992; Sola, 1998; Bresser-Pereira, 2009), essa burocracia foi sendo criada aos poucos a partir das reformas da administração estatal no início dos anos 1930, em especial com as reformas do serviço público promovida pelo DASP, e com o papel ativo do Itamaraty, Banco do Brasil, Sumoc, FGV e BNDES na formação e treinamento de técnicos competentes na área de economia que fizeram carreira no setor público. Nesse sentido, os anos 1930 a 1966 são um período de state-building que materializa a ideologia dos revolucionários de 1930 e que, ao mesmo tempo, produz os agentes capazes não só de operar tais instituições como de reproduzir essa ideologia no interior do aparelho estatal.

O problema da estabilidade da burocracia econômica é fundamental para entender a diferença entre Brasil e Argentina quanto ao assunto em questão. Grande parte da literatura argentina tende a explicar o pífio desenvolvimento industrial desse país em função de sua crônica instabilidade política. No entanto, esse é um problema que afligia os dois países. Brasil e Argentina passaram, entre 1930 e 1966, por número idêntico de golpes de Estado (1930, 1943, 1955, 1962 e 1966 na Argentina e 1930, 1937, 1945, 1954 e 1964 no Brasil). Durante 36 anos, a Argentina teve quinze presidentes, com média de 2,4 anos para cada presidente; durante 34 anos, o Brasil teve onze presidentes, isto é, 3,09 anos para cada presidente. Durante o mesmo período, a Argentina teve 31 ministros da Economia, uma média de 1,16 ano por ministro; o Brasil, por sua vez, teve 25 ministros (45 se contarmos os interinos), uma média de 1,36 ano por ministro (0,75 se contarmos os interinos). Como se pode ver, a instabilidade política é um traço comum a ambos. A diferença é que se desviarmos o nosso olhar da macropolítica para o nível menos visível da administração estatal, veremos que o Brasil contava com a presença estável de uma burocracia econômica que conferiu continuidade à política econômica a despeito das mudanças contínuas na cena política (Perissinotto, 2012).

Tudo foi muito diferente no caso argentino. A literatura especializada traz pou-

Forjaz; 1978; Saes, 1991; Prestes, 1999; Fonseca, 2012. Essa aliança civil-militar fez carreira na história brasileira. Por exemplo, referindo-se ao momento de distenção do regime militar nos países da América Latina, Bresser-Pereira (2003) chama a atenção para importância, no caso brasileiro, da tecnocracia do regime militar e da aliança de classe promovida pelo regime entre esta e o capital. 
quíssimas referências a membros de uma burocracia econômica estável. Apenas grandes nomes, como Raúl Prebisch, Ernesto Malaccorto e Alfredo Gómez Morales, são reiteradamente citados. De fato, Prebisch é muito conhecido como um construtor de instituições e o Banco Central Argentino, fundado em 1935, foi certamente a sua mais famosa realização nesse campo. Contudo, esse processo de construção institucional, que se deu durante os anos 1930, seria, como vimos, dramaticamente revertido nos anos seguintes.

O caso do México, por sua vez, caracteriza-se por maior estabilidade tanto na esfera política quanto na burocracia econômica. Quanto à primeira, tomando como referência o período entre 1934 e 1970, o país teve seis presidentes em 36 anos, média de 6 anos, bastante superior às de Brasil e Argentina. No que se refere à burocracia econômica, tomando como base os dois principais cargos da área (ministros da Fazenda e da Economia) e mantendo o mesmo período como referência, temos médias de 5,14 e 3,6 anos, respectivamente, maiores do que as de Brasil e Argentina. Observe-se ainda que durante todo o período do desarrollo estabilizador $r^{13}$ (1958-1970), período também conhecido como milagre mexicano, o ministro da Fazenda foi o mesmo. Antonio Ortiz Mena se manteve no cargo durantes dois mandatos presidenciais: Adolfo López Mateos (1958-1964) e Gustavo Diaz Ordaz (1964-1970). Essa estabilidade se traduziu numa política econômica substitutiva de importações também bastante estável durante todo o período (Huidobro Ortega, 2012, p. 186, Arès, 2007, p. 212).

Assim, ao compararmos Brasil, México e Argentina a partir da conjuntura crítica criada pela crise de 1929 , percebemos que a presença, nos dois primeiros, de uma elite modernizante, capaz de promover uma coalizão política que sustentasse o seu projeto, de se dedicar à tarefa de construção institucional do Estado Desenvolvimentista e de produzir uma burocracia econômica estável foi fundamental para gerar um padrão duradouro de política econômica industrializante. Ao contrário, no caso da Argentina, a ausência desses fatores nos ajudaria, mais do que a crônica instabilidade política daquele país, a entender o caráter errático do seu desenvolvimento industrial. A surpreendente superação da Argentina por dois países que se encontravam muito atrás dela nas primeiras décadas do século XX não poderia, desse modo, ser explicada sem se levar em conta essa diferença fundamental.

\section{CONCLUSÃO}

O breve ensaio de comparação histórica feito neste texto sugere que, numa conjuntura crítica como a da crise das sociedades primário-exportadoras em 1929, a presença de um grupo político disposto a assumir um projeto modernizante para

\footnotetext{
${ }^{13}$ Ver, entre outros, Soliz (1968); Ortiz Mena (1969); Reynolds (1977); Alejo (1984); Garrido (2002); Huerta e Presa (2003).
} 
a nação é fundamental (embora não suficiente) para explicar as diferenças de desempenho no processo de industrialização nos três países analisados.

Evidentemente, não se trata de pensar tais grupos como uma espécie de Deus ex machina capaz de modelar o mundo a seu bel-prazer. Há, certamente, uma série de constrangimentos objetivos, de natureza diversa, que limitam a sua ação. No entanto, a presença de um grupo com disposição para tomar decisões desenvolvimentistas parece fazer grande diferença, o que, por sua vez, sugere que os seus atributos (sociais, políticos, ideológicos) devem ser analisados comparativamente para entender o seu impacto sobre o desenrolar do processo histórico. Nos mesmos termos colocados por Weber no início deste artigo, a "crença" sobre o desenvolvimento econômico, para ser efetiva, precisa ser incorporada por um grupo disposto a realizá-la na prática e o sentido dessa realização dependerá, em grande parte, das características socialmente significativas dos seus membros. Dito de outra forma, a sociologia comparativa das elites estatais deve ser um componente central dos estudos sobre o desenvolvimento econômico.

O tema, é claro, tem evidentes implicações práticas e atuais. Hoje, quando o Brasil coloca-se novamente numa nova situação de escolha quanto ao padrão de desenvolvimento a ser seguido, quando alguns autores falam até mesmo em um "novo desenvolvimentismo" (Diniz \& Boschi, 2003; Bresser-Pereira \& Diniz, 2009), parece-nos que o tema em questão é de primeira ordem. Se um desenvolvimento econômico pautado na sofisticação tecnológica e na justiça social, por exemplo, apresenta-se como um projeto economicamente plausível no Brasil, então a primeira coisa a saber é quais seriam os grupos sociais disponíveis na sociedade brasileira (e no interior do Estado) capazes de assumir tal projeto, levá-lo adiante politicamente e, por fim, tornar factível o que, a princípio, é apenas possível. Além disso, como as características sociais e ideológicas desses grupos, seus "interesses materiais e ideais”, para utilizar a expressão de Max Weber (1979, p. 315), poderiam afetar o conteúdo e a direção desse projeto? Essas questões permitem tirar a discussão em torno do desenvolvimento brasileiro do terreno estrito das "soluções econômicas" para redefini-lo como aquilo que efetivamente é: um problema político.

\section{REFERÊNCIAS BIBLIOGRÁFICAS}

Albertini J.; Castiglioni, F. M. (1985) "Política e ideologia en la industrialización argentina”. Boletín Informativo Techint, 239: 1-14.

Alejo, F. J. (1984) "Crecimiento, estabilidade y distribución: los três grandes problemas del desarrollo: o caso de México”. El trimestre económico, v. 51, 1, p. 33-72.

Alonso, A. (2007) “De positivismo e positivistas: interpretações do positivismo brasileiro". In: H. Trindade (org.), O positivismo. Teoria e prática. Porto Alegre, Editora da UFRGS: 147-178.

Arés, M. (2007) "El Estado empresário: nacional financeira durante la industrialización por sustitución de importaciones (1934-1994)”. Foro Internacional, v. XLVII, n. 2, abril-junio, pp. 201-244. El Colegio de México.

Bellini, C. (2006) “El grupo Bunge y la política económica del primer peronismo. 1943-1952”. Latin American Research Review, 41 (1), p. 27-50. 
Benevides, M. V. M. (1979) O governo Kubitschek: desenvolvimento econômico e estabilidade política. Rio de Janeiro: Paz e Terra.

Bielschowsky, R. (2000) O pensamento econômico brasileiro. O ciclo ideológico do desenvolvimentismo. Rio de Janeiro: Contraponto.

Boschi, R. (1979) Elites industriais e democracia. Rio de Janeiro: Graal.

Bosi, A. (1992) "A arqueologia do Estado-providência: sobre um enxerto de ideias de longa duração". In: Bosi, A. (ed.), Dialética da colonização. São Paulo: Companhia das Letras: p. 273-307.

Brennan, J. P. (1997) "Industriales y bolicheros: la actividad económica y la alianza populista peronista, 1943-1976”. Boletín del Instituto de Historia Argentina y Americana, 15: 101-141.

Bresser-Pereira, L. C. (2003) Desenvolvimento e crise no Brasil. $5^{\text {a }}$ ed. São Paulo: Editora 34.

Bresser-Pereira, L. C. (2009) Getúlio Vargas: o estadista, a nação e a democracia. Texto para discussão. FGV.

Bresser-Pereira, L. C. e Diniz, E. (2009) “Empresariado Industrial, democracia e poder político". Novos Estudos CEBRAP, $\mathrm{n}^{\circ}$ 84, julho.

Bulmer-Thomas, V. (1998) “The Latin American Economies, 1929-1939”. In: L. Bethel (ed.), Latin America: Economy and Society since 1930. Cambridge: Cambridge University Press, p. 65-114.

Caravaca, J, Plotikin, M. (2007) "La constitución del campo de los economistas estatales en la Argentina. 1910-1935". Desarrollo Económico, Ides, v. 47, n. 187, p. 421-428.

Collier, R. B, Collier D. (1991) Shaping the Political Arena. Princeton: Princeton University Press.

Coniff, M. L. (1978) “A New Perspective on Brazilian Revolution of 1930”. Journal of Latin American Studies, v. 10, n. 1, p. 61-82.

Cortés, Conde R. (2009) The Political Economy of Argentina in the Twentieth Century. Cambridge: Cambridge University Press.

Costa, V. (1991) “As origens do corporativismo brasileiro". In Boschi, R. R. Corporativismo e desigualdade: a construção do espaço público no Brasil. Rio Fundo/IUPERJ.

Daland, R. T. (1967) Brazilian Planning. Development, Politics, and Administration. North Carolina: The University of North Caroline Press.

Diniz, E. (1978) Empresário, Estado e capitalismo no Brasil: 1930/1945. Rio de Janeiro: Paz e Terra.

Donghi, T. H. (2004) La República imposible (1930-1945). Buenos Aires: Ariel Historia.

Dorfman, A. (1983) Cincuenta años de industrialization en la Argentina (1930-1980). Buenos Aires: Ediciones Solar.

Dosman, E. (2001). Raúl Prebisch (1901-1986). A construção da América Latina e do Terceiro Mundo. Rio de Janeiro: Contraponto.

Draibe, S. (1985) Rumos e metamorfoses. Estado e industrialização no Brasil: 1930-1960. Rio de Janeiro: Paz e Terra.

Evans, P. (1995) Embedded Autonomy. States and Industrial Transformation. Princeton: Princeton University Press.

Fausto, B. (1990) “A crise nos anos vinte e a Revolução de 1930". In B. Fausto (org.), História Geral da Civilização Brasileira. O Brasil Republicano (Sociedade e Instituições, 1889-1930). Rio de Janeiro: Difel.

Fausto, B. (1996) História do Brasil. $4^{a}$ Ed. São Paulo: Edusp.

Fausto, B. (1997) A Revolução de 1930: historiografia e história. São Paulo: Companhia das Letras.

Fausto B.; Devoto F. J. (2004) Brasil e Argentina: um ensaio de histórica comparada (1850-2002). São Paulo: Editora 34.

Ffrench-Davis, R.; Muñoz O., Palma, J. G. (1998) “The Latin American Economies, 1950-1990”. In: L. Bethell (ed.), Latin America. Economy and Society since 1930. Cambridge: Cambridge University Press, p. 149-237.

Fonseca, P. C. D. (1987) Vargas: o capitalismo em construção (1906-1954). São Paulo: Editora Brasiliense.

Fonseca, P. C. D. (2011) “Gênese e precursores do desenvolvimentismo no Brasil”. In: P.P.Z. Bastos e P.C.D. Fonseca (orgs.), A era Vargas. Desenvolvimentismo, economia e sociedade. São Paulo, Editora da Unesp, p. 21-50. 
Fonseca, P. C. D. (2003) "Sobre a intencionalidade da política industrializante do Brasil na década de 1930". Revista de Economia e Política, vol. 23, nº 1 (89), janeiro-março, p. 133-148.

Fonseca, P. C. D. (2012) “A Revolução de 1930 e a Economia Brasileira”. Revista Economia, Set-Dez, p. 843-866.

Forjaz, M. C. S. (1978) Tenentismo e Aliança Liberal (1927-1930). São Paulo: Polis.

Galvêas, E. (1990) Ernane Galvêas I (depoimento, 1989). Rio de Janeiro, CPDOC/Banco Central do Brasil. 52 p. dat.: 8 .

Gambini, H. (2007a) Historia del peronismo. El poder total (1943-1951). Buenos Aires: Editora Vergara.

Gambini, H. (2007b) Historia del peronismo. La obsecuencia (1952-1955). Buenos Aires: Editora Vergara.

Garrido, C. (2002) “Industrialización y grandes empresas en el desarrollo estabilizador, 1958-1970". Análisis Económico, n. 35, v. 17, p. 233-267. UNAM, México.

Geddes, B. (1990) “State Autonomy in Brazil, 1930-1964”. Comparative Politics, 22, 2: p. 217-235.

Gerschenkron, A. (1976) Economic Backwardness in Historical Perspective. A Book of Essays. Cambridge: Harvard University Press.

Gomes, A. M. C. (1979) Burguesia e trabalho. Política e legislação social no Brasil. Rio de Janeiro: Campus.

Gouvêa, G. P. (1994) Burocracia e elites burocráticas no Brasil. São Paulo: Editora Paulicéia.

Graham, L. S. (1968) Civil Service Reform in Brazil. Principles versus Practice. Austin: University of Texas Press.

Hamilton, N. (1981) "State Autonomy and Dependent Capitalism in Latin America". British Journal of Sociology, 32, 3, p. 305-329.

Heinz, F. M. (2009) "Positivistas e republicanos: os professores da Escola de Engenharia de Porto Alegre entre a atividade política e a administração pública (1896-1930)". Revista Brasileira de História, 29, 58: 263-289.

Hentschke, J. R. (2004). Positivism Gaúcho-Style. Germany: WVF.

Hirschman, A. O. (1964) The Strategy of Economic Development. New Haven: Yale University Press.

Huerta, H. M.; Presa, Maria F. C. (2003) “Tres modelos de política económica en México durante los últimos sesenta años”. Análisis Económico, v. 18, n. 37, p. 55-80. UNAM, México

Jauregui, A. P. (2000) "La regulación econômica y la representación corporativa en la Argentina y el Brasil”. Revista de Sociologia e Política, 14: 61-75.

Jauregui, A. P. (2004). Brasil y Argeentina: los empresários industriales - 1920-1955. Buenos Aires: Imago Mundi.

Leff, N. (1968) Economic Policy-Making and Development in Brazil, 1947-1964. New York: John Wiley \& Sons, Inc.

Leftwich, A. (2000) States of Development. On the Primacy of Politics in Development. Cambridge: Polity Press.

Leopoldi, M. A. P. (1992) "Burocracia, empresariado e arenas decisórias estratégicas: trajetórias do neocorporativismo no Brasil (1939-1955)”. Ciências Sociais Hoje. Rio de Janeiro, Rio Fundo/ Anpocs, p. 74-101.

Leopoldi, M. A. P. (2000) Política e interesses na industrialização brasileira. As associações industriais, a política econômica e o Estado. Rio de Janeiro: Paz e Terra.

Loureiro, M. R. (1997) Os economistas no governo. Gestão econômica e democracia. Rio de Janeiro: Editora da Fundação Getúlio Vargas.

Love, J. (1988) "Structural change and Conceptual Response in Latin American and Romania, 18601950”. In: Love J.; Jacobsen N. (editors), Guiding the Invisible Hand. Economic Liberalism and the State in Latin American History. New York: Praeger Publishers, p.1-33.

Luna, M. L. S. (2009) "Nacional Financiera, balance y perspectivas del pilar industrial de la banca de desarrollo". Economia Informa, n. 361, p. 80-94.

Maxfield, S. (1993) “The Politics of Mexican Financial Policy”. In: Stephan Haggard, Chung H. Lee y Sylvia Maxfield (dirs.), The Politics of Finance in Developing Countrie., Ithaca, Cornell University Press, pp. 230-258. 
Mallon, R. D.; Sourrouille, J. V. (1975) Economic Policymaking in a Conflictive Society: The Argentine Case. Cambridge: Harvard University Press.

Martins L. (1976) Pouvoir et développement économique. Formation et evolution des structures politiques au Brésil. Paris: Éditions Anthropos.

Merrick, T. W. (1998) “The population of Latin America, 1930-1990”. In: L. Bethell (ed.), Latin America. Economy and Society since 1930. Cambridge: Cambridge University Press: 3-64.

Morales, A. G. (1990) “Alfredo Gómes Morales”. In: Di Tella G. and Braun C. R. (editors). Argentina, 1946-83: The Economic Ministers Speak. London/Oxford: MacMillan/St. Antony’s College; p. 31-46.

Noll, M. I. (2007) “O positivismo e as origens do varguismo". In: H. Trindade (org.), O positivismo. Teoria e prática. Porto Alegre, Editora da UFRGS: 229-270.

Nunes E. (1997) A gramática política do Brasil. Clientelismo e insulamento burocrático. Rio de Janeiro: ENAP/Jorge Zahar Editor.

Ortega, M. A. H. (2012) "Breve historia de la banca de desarrollo mexicana”. Análisis Económico, n. 65, v. XXVII, p. 171-206. Azcapotzalco, Ciudad de México, Distrito Federal.

Ortiz Mena, A. (1969) "Desarrollo estabilizador: una década de estrategia económica en México". El Trimestre Económico, v. 37, n. 146, p. 417-449. Fondo de Cultura Económica, México.

Ortiz Mena, A. (2000) El desarrollo estabilizador: reflexiones sobre una época.

México: fce.

Perissinotto, R. M. (1994) Classes dominantes e hegemonia na República Velha. Campinas: Editora da Unicamp.

Perissinotto, R. M. (2012) "Burocracia econômica e industrialização no Brasil (1930-1966): Notas para uma futura comparação com o caso argentino”. 36 Encontro Anual da Anpocs, Águas de Lindoia.

Potash, R. A. Perón y el G.O.U. (1984) Los documentos de una logia secreta. Buenos Aires: Editorial Sudamericana.

Prestes, A. L. (1999) Tenentismo pós-30. Continuidade ou ruptura? Rio de Janeiro: Paz e Terra.

Reynold, C. W. (1977) “Por qué el 'desarrollo estabilizador' de México fue em realidade desestabilizador”. El Trimestre Económico, v. 44, n.176, p. 997-1023, octubre-diciembre.

Romero, J. L. (2005). Las ideas politicas en Argentina. Buenos Aires: Fondo de Cultura Económica.

Romero, L. A. (2006) História contemporânea da Argentina. Rio de Janeiro: Jorge Zahar Editor.

Rouquié, A. (1975). Radicales y desarrollistas. Buenos Aires: Schapire Editor.

Santín, O. (2001). The Political Economy of México’s Financial Reform. Ashgate.

Saes, D. A. M. de. (1991) “Classes médias e política no Brasil (1930-1964)”. In: B. Fausto (org.), História Geral da Civilização Brasileira. O Brasil Republicano (Sociedade e Política, 1930-1964). Rio de Janeiro: Difel, 447-506.

Santos, R. B. (2006) A Assessoria Econômica da Presidência da República. Contribuição para a interpretação do segundo governo Getúlio Vargas (1951-54). Campinas, Universidade Estadual de Campinas, Instituto de Economia, dissertação de mestrado.

Sábato, J. F. (1988) La clase dominante en la Argentina Moderna. Formación y características. Buenos Aires: CISEA Grupo Editor Latinoamericano.

Schneider, B. R. (1991) Politics within the State. Elite Bureaucrats and Industrial Policy in Authoritarian Brazil. Pittsburgh: University of Pittsburgh Press.

Schneider, B. R. (2004) Business Politics and the State in Twentieth-Century Latin-America. Cambridge: Cambridge University Press.

Segóvia, R. (1968) "El nacionalismo mexicano: los programas políticos revolucionários". Foro Internacional, v. 8, n. 4, apr.-jun., p. 349-359. El Colegio de México.

Sidicaro, R. (2002) Los tres peronismos. Estado y poder económico (1946-55/1973-76/1989-99). Buenos Aires: Siglo Veintiuno Editores Argentinos.

Sikkink, K. (1991) Ideas and Institutions. Developmentalism in Brazil and Argentina. Ithaca/London: Cornell University Press.

Skocpol, T. e Somers, M. (1997). “The Uses of Comparative History in Macrosocial Inquiry”. In: T. 
Skocpol (ed.), Social Revolutions in the Modern World. Cambridge, Cambridge University Press: 72-95.

Sola, L. (1998) Ideias econômicas, decisões políticas. São Paulo, Edusp/Fapesp.

Solís, L. M. (1969). "La política económica y el nacionalismo mexicano”. Foro Internacional, v. 9, n. 3, ene-mar, p. 235-248. El Colegio de México.

Thorp, R. (1998) “The Latin American Economies, 1939-1950”. In: Bethel L editor. Latin America: Economy and Society since 1930. Cambridge: Cambridge University Press: p.115-148.

Topik, S. (1988) "The Economic Role of the State in Liberal Regimes: Brazil and Mexico Compared, 1888-1910". In: Love J, Jacobsen N editors. Guiding the Invisible Hand. Economic Liberalism and the State in Latin American History. New York: Praeger Publishers: p.117-144.

Trimberger, E. K. (1978) Revolution from Above. Military Bureaucrats and Development in Japan, Turkey, Egypt, and Peru. New Jersey: Transaction Books.

Waisman, C. H. (1987) Reversal of Development in Argentina. Postwar counterrevolutionary Policies and Their Structural Consequences. Princeton: Princeton University Press.

Weber, M. (1979) “A psicologia social das religiões mundiais". In: H. H. Gerth e CC. Wright Mills (orgs.). Ensaios de Sociologia. Rio de Janeiro, Zahar: 309-46.

Willis, E. J. (1995) "Explaining Bureaucratic Independence in Brazil: The Experience of the National Economic Development Bank". Journal of Latin American Studies, v. 27, n. 3 (October): 625-661.

Wirth, J. D. (1970) The politics of Brazilian Development (1930-1945). Stanford: Stanford University Press.

Wynia, G. W. (1978) Argentina in the Postwar Era. Politics and Economic Policy Making in a Divided Society. Albuquerque: University of New Mexico Press. 